\title{
Enunciación
}

\section{Infancia y razón evaluadora: contrariedades y resistencias pedagógicas (entre filosofía y literatura)}

\author{
Childhood and evaluative reason: oppositions and pedagogical resistances \\ (between philosophy and literature)
}

\author{
Facundo Giuliano*
}

\begin{abstract}
Resumen
El presente artículo enseña algunas de las formas que toma la razón evaluadora en la educación contemporánea y, en particular, en cierta filosofía de la educación. La travesía combativa propuesta, que busca alimentar una crítica de la razón evaluadora, abreva en fuentes de la literatura para retratar alguna de las formas en cuestión, así como también para pensar en modos de resistencia a estas. De este modo, se pretende avistar horizontes de alteridad que interrumpan la sinonimia que la modernidad/colonialidad instaló entre educación y evaluación, al tiempo que se discute el culto que dicho tipo de racionalidad promueve en determinados planteos filosófico-educativos. En este contexto, podrá observarse cómo la cuestión de la infancia, enfrentada a la razón evaluadora, puede llegar a claudicar sus términos y quedar como una infancia en cuestión a partir de la prerrogativa del culto evaluacionista. Esto último no impedirá situar el antagonismo entre la infancia y las mañas de un culto que intenta seducir mediante juegos rituales adornados con palabras como democracia, control público y mundo compartido. Luego, mediante una búsqueda de lo intersticial, de una pedagogía que dé pelea y dé una corrección otra que se instale en la educación como un tiempo colectivo de infancia y solidaridad con un entramado artesanal/textual, siempre conducente a una parte otra siempre conjetural (más allá de normas y jerarquías). El desenlace está dedicado a la pregunta por el final de la infancia y de su verdugo como una imposible conclusión, ya que la lucha (pedagógico-literaria) continúa.
\end{abstract}

Palabras clave: infancia, filosofía de la educación, literatura latinoamericana, evaluación, pedagogía.

\begin{abstract}
The present article teaches some of the forms that the evaluative reason takes in contemporary education and, in particular, in a certain philosophy of education. The proposed combative journey, which seeks to feed a critique of the evaluative reason, abbreviates in sources of literature to portray some of the forms in question, as well as to think of ways of resistance to them. In this way, it is intended to see horizons of otherness that interrupt the synonymy that modernity/coloniality installed between education and evaluation, while discussing the cult that this type of rationality promotes in certain philosophical-educational approaches. In this context, it will be seen how the question of childhood, faced with evaluative reason, can come to surrender its terms and remain as a childhood in question from the prerogative of the evaluationist cult. The latter will not prevent us from locating the antagonism between childhood and the tricks of a cult that tries to seduce through ritual "games" adorned with words such as "democracy", "public" control and "shared world". Then, through a search for the interstitial, for a pedagogy that gives fight and another corection that is installed in education as a collective time of childhood and solidarity with an artisanal / textual framework always conducive to another part, always conjectural (more beyond norms and hierarchies). The outcome is dedicated to the question of the end of childhood and its executioner as an impossible conclusion, since the (pedagogical-literary) struggle continues.
\end{abstract}

Keywords: childhood, philosophy of education, Latin American literature, evaluation, pedagogy.

\footnotetext{
Doctor por la Facultad de Filosofía y Letras de la Universidad de Buenos Aires. Correo electrónico: giulianofacundo@gmail.com
}

Cómo citar: Giuliano, F. (2020). Infancia y razón evaluadora: contrariedades y resistencias pedagógicas (entre filosofía y literatura). Enunciación, 25(2), 220-231. https://doi.org/10.14483/22486798.16294

Artículo recibido: 12 de mayo de 2020; aprobado: 14 de julio de 2020 


\section{Antesala: pequeño retrato de quien evalúa y una honda (literaria) para darle batalla}

Ojalá nadie se encuentre en ese espejo, aunque vea su reflejo en alguna ocasión. La novela Evaluador, de Noé Jitrik (2002), podría hacer de espéculo por cuanto permite observar ciertas cavidades del cuerpo tomado por la razón evaluadora $^{1}$, es decir, un cuerpo vencido, decadente, con malestar físico, mentalmente vacío, que lee sin interés, pero elabora juicios y toma decisiones sobre gentes que no conoce, se entrega a una tarea penosa con prensa de prestigiosa, una droga que le mantiene con vida al tiempo que vacía y extermina.

"¡Cuidado con esa palabra!”, alerta Jitrik (2002, p. 12). Evaluación es una palabra tobogán porque, dependiendo la fuerza que tome, no se sabe a dónde se puede terminar. En ella, hacer justicia incluye rebanar presupuestos, cortar cabezas, condenar a la disolución, muchas veces con un placer dispendioso. Dice constituir la "garantía de un determinado desarrollo cultural, social y aun políti$\mathrm{Co}^{\prime}$, aunque se sepa que "ninguna evaluación es realmente confiable" (Jitrik, 2002, pp. 23-33). Evaluar, también detestable derecho para conceder o quitar, reconocer y condenar.

Su agente, quien evalúa, tiene un lugar predeterminado en esa maquinaria que no deja de presentar fallas, aunque escruta la atmósfera o mide los ángulos de la luz, la realidad se le escapa por todas partes y por eso vive a base de tres cuartos de conjeturas y un cuarto de desencanto. Es la encarnación de la indiferencia ya que no mira su entorno y menos aun el ajeno (aunque sucedan desgracias o catástrofes), decide lo que valen los otros y ese es su poder vicario (¿sicario?) -decide sobre la vida y la existencia de los demás-, otorga

1 Se trata del tipo de racionalidad que impele a medir, comparar, normalizar y clasificar singularidades en función de su distancia o cercanía respecto de un ideal de sujeto y una representación pedagógica que oficia de norma e indica quiénes quedan dentro (de lo que se considera normal o aprobado) y quiénes quedan fuera (a partir de lo que se considera desaprobado o anormal), procedimientos que involucran dimensiones racistas y mercantiles, tal como se analiza en Giuliano (2019a). cifras (o números) y quita nombres propios. Su preparación es "para el olvido incluso de su propia desdicha, con más razón de la desdicha ajena, el problema ajeno, la suerte ajena, la muerte ajena" (Jitrik, 2002, p. 124).

En su Radiografía de la pampa, Martínez Estrada (2011) dice que la base de toda evaluación radica en el dominio, porque "se cotiza lo que está quieto, lo que se sustrae a la aventura" (p. 314). También cuenta cómo "la severidad de los examinadores suele estar condicionada según un pacto inexistente de transacciones tácitas" (Martínez Estrada, 2011, p. 384), lo que hace que aprobar sea una pequeña victoria contra el profesor verdugo, contra la enseñanza devenida evaluación y contra la universidad (o la escuela) transformada en casa de exámenes. Como si las formas del estudio ya se tornaran estrategias aventureras de lucha y necesitemos, cual hondero entusiasta, tomar fragmentos (de suelo, de texto, de vida) como piedras, "estirar el resorte, enfocar la horqueta y disparar, no dejar de disparar contra la infamia, contra el olvido, contra el general, contra el grupo atareado en la muerte, contra el sepulturero y su lugarteniente" (Mercado, 1994, p. 70), es decir, contra evaluadores, controladores y quienes piensan lo educativo en términos de eficacia, rentabilidad y utilidad. Una manera tal vez de no sumirse a la decadencia disciplinaria que encierra la reflexión e impide ver, entre otras cosas, a la filosofía de la educación como "un esfuerzo por pensar las implicaciones más grandes de la práctica educativa" que posibilite un "acto de suspensión teleológica", esto es, "cuando una disciplina suspende su propio centro de atención debido a su compromiso con cuestiones más grandes que la disciplina misma" (Gordon, 2013, p. 60).

Por último, antes de entrar al ruedo, ataques y defensas se montan sobre una inocultable fragilidad: una que entiende que la amistad no está en la obsecuencia, sino en arrimar el corazón máximamente cerca cuando se opone resistencia. 


\section{La cuestión de la infancia y la infancia en cuestión: un giro de su potencia a su (d)evaluación}

Una de las revueltas planteadas en el ámbito que se conoce como filosofía de la educación, ha sido impulsada por Walter Kohan (2007) en lo que respecta a la subversión de los términos moderno/coloniales que estructuran la relación entre infancia y educación. Desde su planteo, la infancia es un símbolo de la afirmación, un espacio de libertad,

[...] una metáfora de creación en el pensamiento, una imagen de ruptura, de discontinuidad, de quiebra de lo normal y de lo establecido [...]. En cuanto afirmación de la inquietud, la infancia lucha por un espacio que formas de pensamiento totalizadoras en la filosofía occidental le bloquean de manera obstinada a lo largo de su historia. (Kohan, 2007, pp. 130-133)

Así es que la infancia en su inquietud lucha, batalla, renace frente a un sistema que históricamente la asoció a la inmadurez, a la minoridad como representación de la incapacidad, de la falta de resolución o la insolvencia en el uso de las propias capacidades. De modo que la modernidad/ colonialidad y su educación ilustrada la ubicaron como un estado o fase que habría que superar, abandonar, incluso silenciar, en aras de emanciparse, hacerse mayor de edad (Kant), dueño de sí, y vivir con razón al amparo de la luz de un conocimiento pretendidamente universal y neutral. Claro que no se puede pensar en tal superación sin su contracara de abandonos y silenciamientos, por decir solo un poco de la historia de la colonialidad que nos atraviesa también ${ }^{2}$. Si bien

2 Una genealogía de la colonialidad pensada en clave pedagógica y que muestra a la razón evaluadora como uno de sus principales productos puede encontrarse en Giuliano (2019b). No obstante, siguiendo ese trazo, puede advertirse como un rasgo importante de la colonialidad pedagógica que busca colaboradores y servidores disciplinados (devotos fieles) y/o disciplinantes (policías de la colonialidad) que divulguen su credo clasificador mediante el influjo de ese poder pedagógico que instruye en adorar lo prestigioso o semisagrado que el patrón hegemónico cultural establece como tal en nombre de algún universalismo abstracto o imperialista de turno.
Kohan (2007) no atiende específicamente este último problema, su apuesta política lo toca en ciertos sentidos cuando propone a la infancia como una condición de ser afectados que nos acompaña toda la vida, una "singularidad silenciada que no puede ser asimilada por el sistema" y que es necesario recuperar, mantener, no dejar que se vuelva (o nos la vuelvan) a perder. No se trataría de una idealización, o una romantización, o la promoción de una infantilización, tampoco de la restauración de una naturaleza o un orden trascendente, sino de una cuestión política: "una apuesta por la igualdad de los diferentes, por la no jerarquía, por la no representatividad, a cualquier nivel en que se manifiesten" (Kohan, 2007, p. 279). Se trata de la primacía de la pregunta " ¿y si las cosas fueran de otro modo...?", del nacimiento incesante marcado por el ritmo de una supervivencia recurrente que no tiene métrica ni medida porque es precisamente lo inmedible, lo incapturable, lo impactado e impactante, lo infaltable, lo indiferente al número $y$, por ende, a los presupuestos.

Desde tal planteo se entiende la contundencia con la que pueden criticarse técnicas del poder disciplinar como el examen que reduce la enseñanza a una perpetua comparación, medición y sanción de sujetos que, al ser examinados, son por ello identificados, señalados, descritos, casificados, clasificados, juzgados, normalizados y/o excluidos por la razón evaluadora misma que se alimenta de estos procedimientos y da razón, propiedad, certeza e ilusión de madurez o mayoría de edad a quien los ejecuta y a quien los introyecta/ legitima sin resistencia. Además de compartir la base de esta crítica, Kohan alerta sobre el papel del Estado que, en complicidad con el mercado, genera y gestiona políticas educativas evaluadoras cuyos dispositivos examinadores implicados jerarquizan, dividen, premian, castigan y fomentan la competición entre sujetos e instituciones que son tratados(as) por una parafernalia mercadológica (Kohan, 2007, p. 114). A esto podríamos sumarle el testimonio de un breve intercambio público mantenido en 2013 con Kohan a propósito de la 
evaluación y que él mismo, por aquel entonces, la reconocía como un problema filosófico porque:

- La experiencia de pensamiento no se evalúa.

- Todo lo que introduzca un valor condiciona el pensamiento.

- Si la filosofía no tiene contenido, ¿qué se podría evaluar?

- No es un lugar filosófico sino de premios, castigos y competencia.

- Habría que correrla de lugar o diluirla.

- La disolución que ha practicado en ocasiones ha estado ligada al principio de "todos aprobados, ¿qué nota quieren? Ahora dediquémonos a pensar".

- ¿Sería lo que da sentido a una práctica?

Estas líneas no desentonan con la mirada de la escuela como scholè, como tiempo libre que separaría a "los que se educan en la filosofía de los que se educan en los tribunales" porque "hay algo de don y de abandono, inescrutable, infinito, inabarcable en esto de enseñar y aprender" (Kohan y Bárcena, 2017, pp. 30-43). Ahora bien, en un texto reciente escrito junto a Jorge Larrosa, publicado en el libro Viajar para vivir: ensayar. La vida como escuela de viaje, de Kohan, encontramos que la evaluación es planteada como uno de esos ritos del juego académico, que se repite hace siglos, cambia -a veces- sus formas o se recrea, viste ropajes diferentes o muestra gracias distintas que verifican un

Equilibrio difícil entre la máscara y la materia, tan complejo es saber lo que de verdad se juega en cada rito examinador. Las marcas culturales e institucionales son innegables, como también lo son los espacios y los tiempos, los repartos de los cuerpos y de las voces, la distribución de los roles y de las posiciones. Sin embargo, algo parece atravesar esas distancias, algo tal vez propio del gesto pedagógico más genuino, de lo que se juega en todo tiempo y lugar cada vez que se encuentran los caminos de un profesor y un estudiante para pensar en lo que han hecho juntos, en el valor del encuentro, de los saberes compartidos, del espacio y el tiempo vividos en común. Y más aún cuando ese gesto se hace en presencia de otros "oyentes" (el así llamado "tribunal") que también interrogan, critican, sugieren, juzgan y valoran, colocando sus palabras en relación con esos profesores y esos estudiantes, mirándolos de reojo, tratando de hacerse cargo de qué y cómo se ha hecho, de qué y cómo se ha pensado, de qué y cómo se hace público su trabajo. $\mathrm{O}$, dicho de otro modo, tratando de experimentar, con relación al trabajo de otros, qué significa hacer, qué significa pensar, qué significa aprender y qué significa hacer público en educación. En un momento como el nuestro en que la universidad parece repetirse y vaciarse de sentido en sus rituales más propios, hay veces que algunos de esos ritos nos sorprenden $y$, de alguna manera, nos muestran que hay cosas que todavía valen la pena de ser vividas aunque parezcan un contrasentido en los tiempos que corren. (Kohan y Larrosa, 2015, pp. 101-102)

El giro es, como mínimo, llamativo y complicado de encontrarle una vuelta justificada o entendible. Mejor dejar tal asunto para la historia de las conversiones o de los cambios epocales... Pues aquella imagen de ruptura, de discontinuidad, de quiebra de lo normal y de lo establecido parece ahora guardada en un cajón debajo de la misma mesa donde ahora se re-legitima y se acuerda con el rito evaluador que, al ofrecer alguna sorpresa de vez en cuando, se lo muestra formando parte de las cosas que valen la pena de ser vividas. Lo de valer la pena adquiere una connotación particular en una época donde todo parece tener un precio y donde hasta la pena pareciera tener que ser redituable o valer en el mercado.

Lejos de parecer un contrasentido en los tiempos que corren, el ritual evaluador es incluso parte fundamental de esos tiempos (cronológicos) que corren a las gentes con requerimientos amenazantes, emplazamientos pasibles de aplazo (suspenso o desaprobación), pedidos de consentimiento, exposiciones límites, etc. Por mucho juego que se 
pretenda, la desigualdad y la violencia (en cualquiera de sus formas) que la razón evaluadora produce, también se repite hace siglos, cambia sus ropajes o se recrea, muestra sus (pocas) gracias o sus muecas más sutiles y grotescas, verifica más el desequilibrio hacia la máscara (necesaria para la supervivencia a la lógica cruel de dicha racionalidad) que cualquier equilibrismo entre esta y la materia en cuestión, algo que Frantz Fanon (2009) supo mostrar de diferentes maneras en su obra Piel negra, máscaras blancas.

Por eso lo que se juega en cada rito examinador es la vida misma y de ahí que aparezcan tantos fantasmas, tantos miedos, tantos nervios e inseguridades que superar, sortear, saltear (operaciones que recuerdan mucho a lo que los modernos esperaban hacer con la infancia) ... Más que algo digno de ser vivido está mucho más cerca de ser, por todos los vericuetos desigualitarios y trampas normalizadoras que supone, algo indigno a lo que hay que sobrevivir. Como si en ocasiones se tratara de algún tipo de rito de iniciación -con todo lo traumático que suele involucrar-, no es menos importante detenerse en la insistencia de remarcar tal praxis como un rito o un ritual, es decir, como un conjunto de prácticas condensadas en un acto religioso o ceremonial y que regulan (siempre de forma invariable) un culto que aquí correspondería Ilamar evaluacionista (Giuliano, 2020a)². Así como hay de iniciación, también los hay de purificación, de sangre, de consagración, de expiación, pero lo cierto es que siempre responden a un culto, poseen una dimensión invariable y establecen/legitiman un conjunto de prácticas. Por tanto, ¿acaso no será la lógica cruel, desigualitaria y violenta, lo invariable del rito examinador o de los rituales evaluadores?

En el culto evaluacionista (mercantil-competitivo, por decir poco) al que responden sus prácticas iniciadoras, no sería difícil imaginar las formas

3 Sobre el evaluacionismo como religión o culto capitalista en las instituciones educativas, se puede revisar Giuliano (2020a), donde se analizan sus requerimientos en materia de sacrificio y la referencia a sus rituales que actúan como factor de estabilidad/cohesión en comunidades educativas devotas de la razón evaluadora. que pueden tomar sus derramamientos de sangre, expiaciones, purificaciones y consagraciones sin las cuales no habría razón evaluadora. Tampoco hay ritual sin objetivos, ya sea venerar una deidad o rechazar una fuerza que se considera maligna o perjudicial, y sin religión o iglesia. Frente a tales intentos de hacer de la escuela (o la universidad) una iglesia, del pensamiento una religión, del (de la) docente un juez-evaluador, de la enseñanza una deuda a saldar, de la cifra una deidad que siempre tiene algo que rechazar, ¿para la infancia y su inquietud luchadora solo queda el silencio como único chance de que su singularidad no sea asimilada por el sistema?

\section{Más mañas del culto evaluacionista...}

El problema toma mayor gravedad cuando se cree en la razón evaluadora como el gesto pedagógico más genuino que atravesaría las distancias desigualitarias (repartos de cuerpos y voces, distribución de roles y posiciones $)^{4}$ y posibilitaría pensar en lo que estudiantes y docentes han hecho, en el valor de su encuentro, de los saberes compartidos, del espacio y tiempo vividos en común. Como si la educación se tratara de una tasación de encuentros, saberes, espacios y tiempos, cuando no de una subasta al mejor postor. Este sería el triunfo de la lógica mercantil en la educación, que se olvida o deja atrás que la experiencia de pensamiento es in-evaluable, y que donde se introduce valor, el pensamiento está condicionado como a punta de pistola.

4 No se puede soslayar para tal propuesta lo que Cerletti (2012) indica cuando dice que la evaluación educativa "es un procedimiento de normalización que fusiona la transmisión de saberes con prescripciones políticas, culturales y pedagógicas. Constituye una forma de ubicar a cada uno dentro de un orden normal de distribución de lugares a partir de la ponderación de los conocimientos y las prácticas, y de regular sus posibles modificaciones" (pp. 55-57) (énfasis nuestro). Tal necesidad institucional de constatación y control, estratégica por cuanto conforma un estado de cosas y legitima o administra sus eventuales cambios, es compatible con el reparto o división policial de lo sensible a la que Rancière (2010) refiere como la existencia armoniosa (p. 46) entre una ocupación y un equipamiento, entre el hecho de estar en un tiempo y un espacio específico, de ejercer en ellos ocupaciones definidas y de estar dotado de las capacidades, de sentir, de decir, y de hacer adecuadas a esas actividades. Para lo cual la emancipación ha significado, de hecho, la ruptura de este acuerdo entre una ocupación y una capacidad. 
Si las marcas culturales e institucionales son innegables, si la desigualdad es inexorable, si el reparto de los cuerpos y voces o la distribución de roles y posiciones es incuestionable para el culto evaluacionista, lo que se intenta diluir (o eludir y, así, se hace radicalmente antagónica) es precisamente la apuesta por la igualdad de los diferentes, por la no jerarquía, por la no representatividad, a cualquier nivel en que se manifieste. Lo que también desconoce es que las marcas culturales e institucionales también niegan y negar esas marcas abre un procedimiento analéctico que, en cuanto negación de la negación, permite la re-afirmación de la alteridad. De aquí que hacer de la escuela (o la universidad) un juzgado y de su comunidad educativa un conjunto de eventuales tribunales inquisidores supone mirar de reojo a la enseñanza (descuidando lo que de inescrutable, infinito o inabarcable hay en ella), judicializar los vínculos pedagógicos, pedir cuentas sobre lo que se ha hecho o pensado (y cómo), levantar o asumir cargos (y cargas). Otra forma de que la lógica mercantil e inquisitorial triunfe en la educación y reduzca su hacer público al significado de la acción evaluadora, del pensar juzgador y el aprender del culto evaluacionista con todo lo que ello implica.

Asimismo, cualquier incapacidad, falta de resolución o insolvencia puede ser motivo de condena en el marco del culto evaluacionista que por más que no se centre en los contenidos podrá hacerlo en las dichosas formas (incluso de la filosofía que no tendría contenido). Pero ¿de dónde viene esta insistencia en exponer el cuerpo y la voz a situaciones particularmente ritualizadas de manera que los implicados en la causa tengan que dar voz al propio conocimiento, al propio pensamiento, a la propia experiencia y, de alguna manera, encarnarlos/corporizarlos pública y performáticamente para probar su no-indiferencia al mundo compartido?

Podemos ver que la voz, la viva voz, y el cuerpo, el cuerpo presente, son convocados en ciertas situaciones particularmente codificadas y ritualizadas en las que se produce una cierta performance social cuyos rasgos materiales no son en absoluto menospreciables. Pensemos, por ejemplo, en los rituales religiosos en los que las formas litúrgicas y las plegarias (aunque estén escritas y memorizadas) deben ser sin embargo pronunciadas en voz alta. Recordemos también que los procedimientos jurídicos (a pesar de la enorme documentación escrita que los constituye) requieren también de un juicio oral en el que las partes deben estar presentes obligatoriamente (deben "personarse"), y en el que las declaraciones, los testimonios y los juramentos deben pronunciarse verbalmente. $\mathrm{Y}$ no deja de ser interesante que el carácter público y oral de los juicios, que, en nuestra tradición, tiene su origen en la Revolución francesa, esté destinado a garantizar su funcionamiento democrático y su control público, y a evitar el secretismo y las corruptelas. El juicio oral, con todas sus estrictas reglas, fue el instrumento por el cual el sistema jurídico salió de las manos de los especialistas, de su jerga incomprensible y de sus procedimientos secretos y muchas veces arbitrarios para convertirse en algo público y, de alguna manera, de todos. [...] Y los rituales académicos, a veces, exigen la viva voz y el cuerpo presente de modo que todos los implicados tienen, de alguna manera, que dar voz al propio conocimiento, al propio pensamiento, a la propia experiencia y, de alguna manera, encarnarlos pública y performáticamente. [...] Tal vez de eso se trata [...] de no dejar a nadie, ni a sí mismo, indiferente al mundo compartido. (Kohan y Larrosa, 2015, pp. 112-113)

Así parece que fue como la evaluación devino en culto que recicla la herencia cristiana y secular de Occidente al mismo tiempo en los ámbitos educativos, y pasó de ser vista como un lugar de premios, castigos y competencias a ser reivindicada -en conexión con la tradición (europea) de la Revolución francesa- como garantía de funcionamiento democrático y control público que evitaría 
sincretismos y corruptelas o arbitrariedades propias de los especialistas. Pero, tal como el texto enseña, ¿no es precisamente del sincretismo de lo que se constituye la evaluación al conciliar o mezclar en su seno la tradición cristiana (tomando elementos de la confesión $)^{5}$ y la tradición secular francesa (tomando elementos del Ilamado juicio oral)? ¿Será que al purismo doctrinario al que aspira su funcionamiento cuando quisiera evitar el sincretismo refiere a la condición eurocentrada $u$ occidento-céntrica?

A su vez, si la razón evaluadora no funciona sin procesos de imposición e inducción a determinadas formas y contenidos que habría encarnar/ corporizar, ¿no se constituye también con un insoslayable componente de arbitrariedad? En este sentido, cuando se espera que determinados conocimientos, pensamientos y experiencias (por más ajenas o impropias que fuesen) se manifiesten como propias, a partir de la propia voz y el propio cuerpo, ¿tal arbitrio o convención (institucionalizada) no implica de entrada cierta corruptela o soborno menor como modo principal de actuación (a)probatoria? Como si, una vez más, la mascarada fuese condición de posibilidad para la absolución en el juicio, la venia en el examen y la aprobación en la evaluación, es decir, (de)mostrar $^{6}$ "a viva voz y de cuerpo presente" que tales conocimientos, pensamientos y experiencias fueron adecuadamente introyectados o, mejor dicho, apropiados y, por lo mismo, bien repetidos, lo cual sería garante de no haber sido indiferentes a la enseñanza o mundo compartido. De este modo quizá se entienda mejor a la infancia en supervivencia recurrente porque no haría más que enfrentarse a

5 Un análisis detallado de esta arista del problema donde se enseña el lugar de la confesión en la razón evaluadora, evidenciando vínculos y continuidades que hacen de docentes y estudiantes sujetos confesantes, puede encontrarse en Giuliano (2020b).

6 Cerletti (2012) sugiere que cuando se aprueba, en realidad, se prueba algo más que disponer de algunos saberes o competencias, se prueba el merecimiento de un reconocimiento institucional que, en el mejor de los casos, permitiría ascender socialmente. Esta relación entre razón evaluadora y demostración identifica la función docente como tarea de testimoniar o dar fe de una obediencia (o cumplimiento) que autoriza la acreditación de requisitos, formalidades, niveles de conocimiento determinados. la métrica, lo medible, lo capturable, lo pactado y pactante, lo que le falta, lo numérico y lo pre-supuesto. Es la evaluación de la infancia como su devaluación, el paso de un estar inquieto a un ser evaluado o, en caso de éxito, a un ser acreditado que verifica un supuesto político-pedagógico y moral:

[...] supone que la palabra del otro no debe ser simplemente expresada sino probada, y si no hay algún tipo de prueba instituida, esa palabra no tiene valor. Podríamos decir [...] que la esencia del concepto de evaluación contiene el germen de la desconfianza. La desconfianza sería algo así como la hipótesis sobre la que se construye la posibilidad de transmisión institucional del saber, ya que todo aprendizaje debe ser constatado. Esto significa que ningún evaluador puede admitir, sin más, la palabra del evaluado, sino que [...] el evaluado debe rendir cuentas de sus afirmaciones, debe probar lo que dice o hace. (Cerletti, 2012, p. 59)

Entonces no hay razón evaluadora sin desconfianza del otro y presuposición de algún aprendizaje esperado que habrá que demostrar, un aprendizaje que involucra lo que Cerletti (2012) denomina la relación subjetiva con el saber (que la evaluación objetiva) y está dada por la determinación docente sobre si alguien sabe o no, es decir, al tiempo que la función docente se reduciría a regular la relación de alguien con un saber, esta relación es interiorizada por estudiantes (no sin resistencias) a partir de dicha regulación con sus respectivos efectos subjetivantes. El hecho de tener una idea objetivada del aprendizaje le quita lo que este puede tener de inescrutable, de infinito o inabarcable y ubica la docencia en el lugar del testigo institucional y del peritaje inquisitorial.

Así es que se busca medir la transmisión en su proceso (de interiorización) que resultaría en un aprendizaje pretendidamente crono-lógico y verificable por un(a) docente que representaría la institución y el sistema educativo (pero siempre, 
afortunadamente, quedan márgenes de indeterminación o de rebelión). Lo que podría llamarse la dimensión inclusiva de la razón evaluadora muestra que "no solo juzga una tarea asignada, sino que ubica a quien posea o no los conocimientos requeridos, en un lugar del sistema educativo", porque "cuando se evalúa, se discrimina, no solo respecto de un saber adquirido o no, sino respecto de cada uno de los que aprenden, en el contexto particular de ese aprendizaje y respecto del sistema en general" (Cerletti, 2012, p. 60). Ya hemos visto por qué este procedimiento otorga una dimensión social al resultado de una prueba individual y que el mismo no puede pensarse sin las significaciones que una sociedad competitiva y meritocrática le otorga.

Por tanto, el culto evaluacionista que tiene como deidad a la razón evaluadora involucra, ciertamente, procedimientos de imposturas, sincretismos, corruptelas, arbitrariedades, discriminaciones y una escena persistente: alguien que domina un saber utiliza técnicas para transmitirlo a gentes que no y, en última instancia, será el dominador quien dirá si hubo aprendizaje mediante un juicio, un examen o evaluación que pondrá a prueba los procesos de interiorización de la transmisión. Una pregunta inconcluyente quizá podría ser: ¿Quién se dispondrá a interrumpir la escena repetida sobre la que se montan los chanchullos más perversos de Occidente? O mejor colectivamente, ¿qué esperamos para desmontar los escenarios del juicio educativo? ${ }^{7}$.

\section{Pistas para contrarrestar a un profesor verdugo: lo intersticial, una pedagogía de la pelea y una corrección otra}

En estado de memoria, así se llama el libro en que la gran pensadora Tununa Mercado (1990) nos convida algunos argumentos importantes para combatir la razón evaluadora. Por ejemplo, cuando se plantea una situación de competencia, la necesidad imperiosa de huir o el impulso de borrarse

7 En Giuliano (2020c) pueden explorarse diferentes formas que toma la razón evaluadora y sus presupuestos en los escenarios del juicio educativo a partir de las distintas tradiciones literarias, filosóficas y pedagógicas de las que se nutre y que contribuyen a su expansión actual. del campo (al mejor estilo "combatiente que huye sirve para otra lucha") cuando de confrontar méritos se trata, los estados de desvalimiento y fragilidad que impiden un enfrentamiento igualitario o se convierten en un foco inextinguible de ansiedad que se dirime en las propias capacidades de poner a prueba toda la propia existencia, ¿acaso no son las infecciones de dicho tipo de racionalidad?

Alguien que ha trabajado gran parte de su vida junto a quienes se les ha atribuido el significante discapacidad lo dice de una manera contundente: "nadie desea exponerse a la verificación de sus propias capacidades" (Skliar, 2011, p. 103). Por esto es que Tununa Mercado (1990) dice que siempre ha tenido una profunda piedad solidaria con quienes ceden a la imposición de dar prueba de conocimiento, de fuerza o de valor, para pertenecer a alguna esfera de la existencia. De aquí que el hecho de "ser sometida a examen, a juicio, a concurso, a cualquier tribunal", que no es otra cosa que "estar en oposición con un semejante para que alguien establezca un juicio y una calificación", siempre la ha considerado como una "condición humillante y cruel" de la cual se ha apartado con persistencia como quien se aleja de un mal (Mercado, 1990, p. 22) ${ }^{8}$. Aunque algunas veces aceptó exponerse a esas situaciones consideradas extremas, sobre todo para ganarse la vida, señala a la compulsión examinatoria (Mercado, 1990, p. 24) y la imposibilidad de superarla como lo que la dejó fuera de carrera en la universidad, al no pasar los últimos exámenes con un profesor que se apellidaba Verdugo y que condensaba en su sintagma toda una historia de la docencia afincada en la ejecución de las penas y la crueldad que la lógica del juicio pedagógico y la compulsión examinatoria potenciaron en la razón evaluadora.

Su testimonio vivo permite poner en jaque a la razón evaluadora que gusta de penar el error

8 Esta posición ético-política podría inscribirse o dialogar con aquellas herencias indisciplinadas y legados de rebelión que, mediante diferentes apuestas pedagógicas, compartieron esta problematización en movimientos históricos como la Reforma Universitaria de 1918 y el denominado Mayo Francés. Un abordaje detallado de estos antecedentes puede encontrarse en Giuliano (2020d). 
y muestra que el señalamiento de incomprensión siempre es una inferencia falsa porque descuida las zonas de verdadera revelación a las que, por ráfagas, la inteligencia de un libro arroja a alguien, aunque después le devuelva a una parcela estrecha de entendimiento. Como si la materia intelectual se depositara y decantara como la arenilla más leve sin otra intención que la de dejarse alimentar por el calor que irradia, Tununa enseña que (aunque deficitaria) la apropiación intelectual se produce por bocados: cuando intenta morderse el conjunto, las partes se escamotean; cuando se detiene en las partes, el conjunto se vuelve borroso y se anda a los tanteos, soltando o recuperando lo captado, "atesorando apenas los fondos de la gran caldera" (Mercado, 1990, p. 140). Como cuando alguien intenta apropiarse de un conocimiento y una distracción o un Ilamado de sirenas, le sustrae de los modos formales en los que suele incorporarse el conocimiento y se transita por un terreno impracticable, y lo que "se debe" leer para saber

[...] se vuelve cada vez más brumoso, mientras que lo que está al costado, por encima o por debajo del texto, sin posiciones jerárquicas, comienza a cobrar nitidez y hacerse de un brillo, desplazando a las sombras los datos que hacen al conocimiento sin más, el que se adquiere y se transmite. (Mercado, 1990, p. 141)

Así, aparece "lo intersticial, esa segunda o tercera piel de lo escrito" que nos saca del meollo de saber y lo que se sabe, o lo que se propone conocer, "no es lo que podría ser exhibido como una adquisición, ni siquiera como una acumulación intelectual" (Mercado, 1990, p. 141, énfasis nuestro).

Se trata precisamente de una posición intelectual anticapitalista que no busca acumular ni ostentar, que da lugar a lo involuntario de la memoria, justamente lo que nos impediría el esnobismo de hacer gala de alguna cita y lo que permitiría que el texto también se escape al tiempo que el naufragio en un balbuceo nos reconduce hacia la infancia.
Así, aunque haya textos que permiten inmersión y acrobacias regocijantes, o del tipo roca de laderas inabordables y resbaladizas que hacen caer al vacío, lo intersticial nos convida una potencia de infancia que desplaza el dato informe pasible de acumulación y que se abre a esas otras pieles de lo escrito que no se ubican bajo ninguna posición jerárquica. En este sentido, como una figura de lo in-evaluable, lo intersticial se despliega en resistencia al profesor verdugo que le escamotea vida a la enseñanza y en su lugar calcula riesgos conforme a la buena conciencia que inmola a la infancia, porque ponerla frente al abismo es incitarla a arrojarse cuando "nada más que el abismo se le ofrece" (Jitrik, 1959, p. 99).

Por ello, quizá Noé Jitrik (1959) hace hincapié en la enseñanza como el ofrecimiento o la entrega a una experiencia que no deja ganancia o provecho necesariamente, ni logro ni, muchas veces, satisfacción, sino una pérdida de ventaja que verifica que no hay distancia tan fabulosa entre error y verdad, entre cordura y locura, o entre ministro y presidiario. Y esta podría ser su gran cercanía con la literatura, un multi-territorio "donde se triunfa fracasando, donde los escrúpulos son sospechosos" y "el movimiento más ambiguo, le otorga la posibilidad de perder lo que había creído encontrar o de descubrir lo que ya no podrá obtener" (Jitrik, 1959, p. 61). Limitarse entonces a ser el profesor verdugo que la razón evaluadora promueve en cada instancia docente, es también echar mano de lo que Jitrik (1959) llama la pedagogía de Quiroga y consiste en un cierto disponerse a la pelea que es el trabajo, "un ardoroso cuerpo a cuerpo con las cosas" (p. 98) que permite encontrar los límites a la propia miseria.

Algo similar sucede con la corrección cuando se la sustrae de la razón evaluadora y su poder disciplinario, quizá al modo de como solían entenderla artesanos indígenas y tejedoras comunitarias. Es el esfuerzo que Noé Jitrik (2000) realiza en Los grados de la escritura cuando propone separar la corrección de la disciplina, es decir, modificar la relación básica que establece una jerarquía clara entre actividad y pasividad, para entenderla como agonística en el sentido de una lucha que se 
da en relación de exterioridad con todo sistema de cumplimiento de una norma (sea gramatical o social). De modo que enmendar no tiene por objeto un error, sino un interpretar que conduce un entramado (textual/artesanal) a una parte otra siempre conjeturable y que implica mucho más que normas, leyes o distribuciones jerárquicas de bien y mal. Implica la introducción de una diferencia en un gesto propiamente educativo que hace de la corrección un guiar con colaboración y solidaridad, en compañía, admitiendo un orden imprevisto y no pre-establecido.

Siguiendo el planteamiento de Jitrik (2000), corregir sería así una actividad colaborativa, solidaria y colectiva, que se proyecta de manera diferente sobre la historia misma, que ha estado ligada a muchas iniquidades. Lo que supone el convite de una orientación en la recuperación o búsqueda de lo extraviado, una gestualidad que se da siempre junto a (junto al otro, junto al texto, junto a lo que nos junta). Por ende, no puede hacerse desde arriba, lo que conllevaría a la superficialidad y trivialidad en lugar de concentrarse en el sentido que el entramado da a leer (desde donde solo podría proceder la corrección, según esta perspectiva) y que requiere una "renuncia al autoritarismo de aplicación de normas" (Jitrik, 2000, p. 82) para tornarse la tarea social y piadosa que una defensa del sentido en cuestión necesita.

El cese de la corrección, por tanto, apela a cierta sabiduría (en) común y no solo a "la atenuación de los síntomas", algo que Jitrik encontró en Sarmiento cuando este le explicó a Alsina que si no incorporó sus indicaciones fue para que no "desapareciese su fisonomía primitiva" y la "lozana y voluntariosa audacia de la mal disciplinada concepción" (Jitrik, 2000, p. 88), lo cual fue fundamental para la obra en cuestión. Tal vez entonces, en esta idea de corección, algo in-evaluable como cierta indisciplina y una audacia de infancia sean pistas que podrían seguirse en busca de un antídoto para las infecciones que provoca la razón evaluadora. Porque, como diría Martínez Estrada (2011), la vida "es más bien una novela que un alegato" (p. 206).

\section{¿Un final para la infancia o para su verdugo? (A modo de imposible conclusión)}

Lo interesante de la siempre inexacta expresión primera infancia, quizá sea la insinuación del sinnúmero -en apariencia ordenado- de todas las infancias que le continúan. Pero no hay cronología viable que ordene o mande lo que en lo más recóndito de los seres convive en forma sin-crónica, herética, estoica.

La travesía propuesta partió de un retrato que intentó hacer de espejo, o reflejo, enseñante del cuerpo tomado por la razón evaluadora con todos los efectos que tiene sobre huésped. Así nos encontramos con un sujeto pretendidamente soberano, adulto-céntrico, que hace buen uso de su razón, aunque esto implique rebanar cabezas y ejercer un poder sicario sobre otras vidas. Con artilugios y rituales, alimenta el culto evaluacionista que tanto goza con la conversión de cuestiones de infancias en infancias en cuestión.

La (cuestión de la) infancia, que puede decirse equívocamente en singular, es la punta de lanza de un ilimitado plural que involucra un espacio-tiempo de libertad y de invención, así como de discontinuidad y quiebre de lo normal o establecido como tal. Es la inquietud que se afirma sobre una lucha por expropiar un suelo y un tiempo que la modernidad/colonialidad le ha privado a lo largo de la historia y cada vez que la (d)evaluó, la redujo, la patologizó. Así, la infancia (y el no ha lugar de su interpelación) todavía sigue re-negando de sus etiquetamientos asociados a la inmadurez, la incapacidad, la insolvencia, la falta de..., lo cual no es otra cosa que una operación de silenciamiento sobre una singularidad inasimilable, inmedible, incapturable por el sistema.

Quizá sea tan negada y resistida por el jaque mate que puede producir a las jerarquías con una simple pregunta. Irredenta, indómita, insurrecta, intentan convencerla de que se pliegue al juego académico, la seducen anteponiendo la palabra juego, pero no aguantan la tentación de apellidarle su jerarquía y hasta prometen réditos por participar 
de sus ritos repetidos hace siglos que solo varían en los ropajes o en la risa que los jerarcas mismos le causan. En todas esas estrategias o procedimientos, se traza una batalla por la re-existencia de la infancia, precisamente porque desnuda un antagonismo fundamental entre su incógnita y la razón que la evaluación (y su culto) quisieran imponerle contra toda su bella irreverencia, su poética insolencia y su peligrosa inquietud.

El silencio monacal no puede ser el único destino para resguardar la singularidad de cualquier infancia y censurar así toda potencia de manifestación. Por eso, quizá como en el juego del truco, se pueda plantear una contra-flor al resto como un florecimiento antagónico a lo que falta, que no abandona la diferencia, pero la involucra en una acción de contrarresto hacia esas mañas más o menos sutiles con las que el culto evaluacionista nos despoja de infancia. Recordemos algunas de esas mañas, sin repetir y sin (re)soplar -tanto-, acaso por machacar sobre machacado:

- La educación reducida a una tasación de encuentros, saberes, espacios y tiempos.

- La insolvencia, la falta de resolución y la dificultad para exponer el cuerpo y la voz a las situaciones ritualizadas como actitudes pasibles de condena.

- La creencia en procedimientos evaluadores como una manera de no dejar a nadie indiferente del mundo compartido.

- El paso (o la conversión) de la evaluación de ser un lugar de premios, castigos y competencias, casi por arte de magia (cristiana y/o secular), a reivindicarse como garantía de democracia y control público.

- La arbitrariedad, su corruptela constitutiva, toma la forma de una mascarada a la que se asiste mediante un soborno a pagar con una actuación aprobatoria.

- La evaluación de la infancia es su devaluación, el paso de un estar inquieto a un ser evaluado (medido, capturado, comparado, acreditado solo en tanto actúe en aparente conformidad con un supuesto pedagógico-moral).

- La docencia se hace así dominadora y una figura del verdugo incapaz de soportar la potencia de lo intersticial, una pedagogía de la pelea y una corrección otra.

Apenas tres gestualidades mínimas de contrarresto que brotan como aparente maleza entre los mosaicos de la escuela y la universidad que, frente a la abundancia del duro cemento, todavía permiten recordar la ternura de ciertas pasturas.

Tal vez porque la potencia de lo intersticial radica no en lo que se debe saber, sino en lo que está al costado o debajo -sin posiciones jerárquicasde una textualidad: otras pieles de lo escrito que no pueden ser exhibidas como adquisición ni acumulación, un anticapitalismo del saber que convoca al naufragio en un balbuceo que nos instala en la infancia.

Tal vez porque una pedagogía de la pelea es un cuerpo a cuerpo que se ofrece o se entrega a una experiencia sin rédito y con una pérdida de ventaja que enseña las cercanías entre error y verdad en un movimiento sin escrúpulos que limita la propia miseria o le encuentra sus límites.

Tal vez porque una corrección otra reivindica el suelo ancestral del error como verdad de la textura y ofrece una enmienda que interpreta un entramado artesanal conducente a una parte otra siempre conjetural -más allá de lo normal y de las distribuciones jerárquicas-. Quizá como en la experiencia educativa más inolvidable, se trata de una solidaridad que colectiviza un tiempo de acompañar en lo imprevisto y no pre-establecido, una audacia que vincula dos o más infancias en cierta indisciplina novelista del vivir.

\section{Reconocimientos}

Este artículo se deriva de la investigación "Crítica de la razón evaluadora: implicancias ético-políticas en educación", financiada por el Consejo Nacional de Investigaciones Científicas y Técnicas 
(Argentina), y también se articula con el proyecto de investigación FiloCyT "Educación, filosofía y psicoanálisis: la potencia de un anudamiento indisciplinario frente al capitalismo contemporáneo", dirigido por el autor, con sede en el Instituto de Investigaciones en Ciencias de la Educación (UBA).

\section{Referencias bibliográficas}

Cerletti, A. (2012). La evaluación en Filosofía. Aspectos didácticos y políticos. Educar em Revista, (46), 53-68. DOI: http://dx.doi.org/10.1590/ S0104-40602012000400005

Fanon, F. (2009). Piel negra, máscaras blancas. Madrid: Akal.

Giuliano, F. (2019a). ¿Tienes razón evaluación? Notas para la profundización de una noción filosófica de la educación. Revista Electrónica Educare, 23(1), 1-22. DOI: http://dx.doi.org/10.15359/ree.23-1.20

Giuliano, F. (2019b). La razón evaluadora en las pedagogías críticas: reflexiones sobre la colonialidad pedagógica desde América Latina (1954-2019). Revista Estado y Políticas Públicas, 8(13), 145-166. Recuperado de http://hdl.handle.net/10469/15851

Giuliano, F. (2020a). La razón evaluadora entre temporalidades discontinuas y repartición de lo sensible. Del culto evaluacionista a una educación indisciplinada. Cuadernos de Filosofía Latinoamericana, 41(122), 145-186. DOI: https://doi. org/10.15332/25005375/4643

Giuliano, F. (2020b). Portarse mal, decir alguna verdad: la función de la confesión en la razón evaluadora. ENSAYOS, Revista de la Facultad de Educación de Albacete, 35(1), 163-173. DOI: https://doi. org/10.18239/ensayos.v35i1.2282

Giuliano, F. (2020c). Razón evaluadora y escenarios del juicio educativo. Pensamiento Actual, 20(34), 74-90. DOI: https://doi.org/10.15517/ pa.v20i34.41836

Giuliano, F. (2020d). Herencias indisciplinadas, legados de rebelión: derivaciones ético-pedagógicas para una crítica de la razón evaluadora (a 100 años de la Reforma Universitaria del 18 y 50 años del Mayo Francés). Investigación y Postgrado, 35(1), 35-60. Recuperado de http://revistas.upel.digital/ index.php/revinpost/article/view/8499

Gordon, L. (2013). Decadencia disciplinaria. Pensamiento vivo en tiempos difíciles. Quito: Ediciones Abya-Yala.

Jitrik, N. (1959). Horacio Quiroga. Una obra de experiencia y riesgo. Buenos Aires: Ediciones Culturales Argentinas.

Jitrik, N. (2000). Los grados de la escritura. Buenos Aires: Manantial.

Jitrik, N. (2002). Evaluador. México: Fondo de Cultura Económica.

Kohan, W. (2007). Infancia entre educación y filosofía. Barcelona: Laertes.

Kohan, W. y Bárcena, F. (2017). Prólogo. Diez cartas para una conversación. En F. Giuliano, Rebeliones éticas, palabras comunes. Conversaciones (filosóficas, políticas, educativas) con Judith Butler, Raúl Fornet-Betancourt, Walter Mignolo, Jacques Rancière, Slavoj Žižek (pp. 19-44). Buenos Aires: Miño y Dávila.

Kohan, W. y Larrosa, J. (2015). A viva voz y de cuerpo presente. Notas sobre una exposición al final del trayecto. En W. Kohan, Viajar para vivir: ensayar. La vida como escuela de viaje (pp. 101-113). Buenos Aires: Miño y Dávila.

Martínez Estrada, E. (2011 [1933]). Radiografía de la pampa. Buenos Aires: Eudeba.

Mercado, T. (1990). En estado de memoria. Buenos Aires: Ada Korn.

Mercado, T. (1994). La letra de lo mínimo. Rosario: Beatriz Viterbo.

Rancière, J. (2010). El espectador emancipado. Buenos Aires: Manantial.

Skliar, C. (2011). Lo dicho, lo escrito, lo ignorado. Ensayos mínimos entre educación, filosofía y literatura. Buenos Aires: Miño y Dávila. 